Educa-UMCH,15, enero - junio 2020 https://doi.org/ 10.35756/educaumch.202015.106 ISSN: 2617-0337

\title{
Análisis de las raíces violencia social-estructural desde el pensamiento de Tomas Hobbes
}

Root analysis social-structural violence from the thinking of Tomas Hobbes

Recibido: 29 de octubre 2019, Evaluado: 15 de enero 2020, Aceptado: 30 de abril 2020

\section{Como citar el artículo}

Calcín Figueroa, E. (2020). Análisis de las raíces violencia social-estructural desde el pensamiento de Tomas Hobbes. Revista EDUCA UMCH, (15), 93-103. https://doi.org/10.35756/educaumch.202015.106

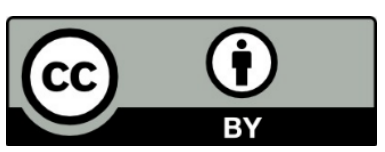

Esta obra está bajo una licencia internacional Creative Commons Atribución 4.0.

revistaeduca@umch.edu.pe revistas.umch.edu.pe 


\section{Resumen}

Hobbes (1588-1679) realizará un análisis de la sociedad a partir de una comprensión materialista del hombre. Su estado de naturaleza lo llevará a un enfrentamiento con los otros hombres que tiene sus mismas aspiraciones de poder y dominio. De esta manera, el Estado como fruto de un pacto entre los hombres tendrá el deber de garantizar la supervivencia de todos los hombres aplicando las leyes, haciendocumplir los deberes y respetar los derechos. Su pensamiento debe leerse dentro del contexto en que surge porque permite comprender la historia y la búsqueda racionalidadde los hechos sociales.

Palabras claves: estado de naturaleza, pacto social, Leviatán, Estado, autoridad.

\section{Summary}

Hobbes (1588-1679) will perform an analysis of society from a materialistic understanding of man. His state of nature will lead him to a confrontation with the other men who have their same aspirations for power and dominion. In this way, the State as aresult of a pact between men will have the duty to guarantee the survival of all men by applying the laws, enforcing the duties and respecting the rights. Your thinking should beread within the context in which it arises because it allows you to understand history and the search for rationality of social facts.

Keywords: state of nature, social pact, Leviathan, State, authority. 


\section{Introducción}

Me detengo frente al kiosco para leer los titulares de los principales diarios de la capital.Éste se encuentra en el paradero cercano a mi casa donde habitualmente abordo el ómnibus cada mañana para ir a mi trabajo. Al leer no puedo dejar de sentir esa sensaciónde estupor y preocupación frente a los acontecimientos que son habituales en nuestra capital. Todos ellos no parecen ser sino recogidos o copiados de un reporte policial de lasdiversas comisarías de Lima. Se leen algunos titulares como estos: Encapuchados asesinan obrero y acribillan a su hermano, Asesinan joven estudiante en discoteca, Roban 70 mil soles a empresario, Hombre paralítico balea a su esposa, etc. Observo quelos lectores de a pie como yo no sienten preocupación frente a los acontecimientos que ocurren a diario en nuestra ciudad. El asesinato de un niño, un joven estudiante, una madregestante, un padre de familia que regresa a casa luego de una larga jornada de trabajo, notienen impacto en la población. No se presenta ese sentimiento de indignación que lleva a cuestionar la necesidad de impeler a actuar a nuestras autoridades. Y lo que es más graveaún a pensar las causas de una violencia que en nuestro país es un problema endémico- estructural. Hemos llegado a convertir nuestra ciudad en "civilización de la violencia". Pero, ¿Por qué una sociedad violenta? ¿Cuáles son las raíces de la violencia? ¿Por qué elhombre es capaz de actuar tan insensiblemente contra el otro? Estas son algunas de las preguntas que trataremos de responder en el presente ensayo a partir del pensamiento deThomas Hobbes.

\section{Consideraciones previas}

Todo grupo humano desde el momento que comparte un mismo medio geográfico y tieneque socializar con otros hombres para acceder a bienes o servicios que por bienestar general deben ser accesibles a todos los miembros de esa misma sociedad, se enfrentan a una situación conflictiva que por su propia naturaleza no tiene que degenerar necesariamente en violencia. "La violencia es el uso abierto u oculto de la fuerza, con el fin de obtener de un individuo o grupo (social, económico, político, cultural, familiar, nacional) algo en lo que éste no quiere consentir libremente". (Comisión Nacional Permanente de Educación para la Paz, 1989, p. 38) Es decir, la violencia es el modo injusto y abusivo de resolver un conflicto.

La violencia ha sido tratada desde diversas perspectivas dentro del ámbito de la reflexión filosófica; así, en La Iliada de Homero esta es vista como una consecuencia de la convivencia humana. La vida misma no puede estar exenta de hechos conflictivos o violentos. Los cantos que se entonan en la obra manifiestan esa visión donde seentremezclan los deseos divinos y humanos. Jacqueline de Romely (2010) manifiesta que se operará una superación en la religiosidad helena donde Zeus pasa de tiránico a ser un dios de justicia que se convertirá en garante del orden cósmico: "Todo se sitúa, efectivamente en una evolución. Vimos como la justicia de Zeus sucedía al caos; vimos como aparecía la benignidad, el perdón y la indulgencia, incluso en las tragedias " (p. 79).De este modo, la capacidad de ejercer autoridad sobre sus dominios como árbitro justo seva institucionalizando frente a sus súbditos. En cambio, desde un análisis sobre el estilo de vida en la polis griega la violencia se evitaba con la resolución de los conflictos entrelos ciudadanos que eran regulados o previstos cuando los cargos públicos eran sorteados; de tal modo, nadie podía postularse a una magistratura motu 
propio.

Los magistrados eran elegidos para ocupar un cargo y eran sometidos a un control mientras lo desempeñaran. Su elección era anual, y al terminar rendían cuentas. Podían ser juzgados por las ekklesias, o asambleas. Sus funciones podían ser legislativas, judiciales, militares y financieras. (Cadavid, 2012, p. 34)

De esta manera, las decisiones políticas eran debatidas por lo políticos, pero consultadasa la Ecclesia (asamblea del pueblo) donde se resolvía la crisis o el conflicto.

Es importante señalar que detrás de estas concepciones que justifican la necesidad de un Estado que regule las relaciones entre los hombres hay una concepción antropológica subyacente. Así, en el pensamiento filosófico griego la búsqueda del cosmos los llevó a centrar su atención en el hombre como parte integrante de ese cosmos. "El problema del hombre es lo que separa el pensamiento socrático del presocrático. Sócrates nunca ataca o critica la teoría de sus predecesores, no pretende introducir una nueva doctrina filosófica". (Cassirer, p. 9). Para Sócrates (470-399 a. C.) la descripción de las propiedades y cualidades de la naturaleza no dicen nada acerca de los humanos, sino susdiversas cualidades y virtudes humanas desde donde se debe revelar la última verdad sobre el hombre. La acción del hombre ha de ser consecuencia de una reflexión del individuo quien dialoga consigo mismo.

La antropología de Platón (427-347 a. C.) desarrolla sistemáticamente esa comprensión del hombre afirmando que lo más importante del hombre no es su cuerpo sino la psyché (alma). Y el alma se alimenta de belleza, sabiduría y bondad. Siento esto de gran importancia para el destino del alma cuando tenga que transmigrar a otro cuerpo. A su vez, el alma humana está formada por tres partes; racional, irascible y apetitiva. Cada una de estas partes relacionándose con la ética y la política. De esta manera, el conocimientoy las virtudes llevarán al hombre a una armonía que se expresará en su condición de individuo y ciudadano. A su vez, Aristóteles (384-322 a. C.) afirmará en el hombre la existencia de un alma que cumple tres funciones: vegetativa, sensitiva y racional. Siendosu ser racional del hombre que lo conducirá a actuar de manera equilibrada en esa búsqueda de la felicidad a través de la práctica de la virtud. Así, el buen ciudadano es aquel quien ha cultivado su espíritu más que con un saber teórico, un saber práctico. Porlo tanto, la polis está conformada por individuos que armonizan sus intereses individualescon las del Estado. La ley y la participación de los ciudadanos en las asambleas constituirán las características de un hombre civilizado.

\section{Situación filosófica-social de su época}

En el devenir de la historia, llegada la modernidad, encontramos al filósofo inglés Thomas Hobbes (1588-1679) quien realizará un análisis de la sociedad a partir de una comprensión materialista del hombre. Su comprensión antropológica deberá situarse a partir de Descartes (1596-1650) quien se concebirá como individuo solitario, encerrado en si mismo y aislado de los demás. No niega la existencia de los demás, sino no lo valora. Esta antropología del yo solitario (egología) si bien tiene un carácter metodológico convierte la realidad en una idea absolutizando la línea racionalista e idealista, absolutiza la importancia de la conciencia que "piensa" el mundo. Frente a esta concepción, la corriente empirista absolutizará la 
importancia del mundo material y del cuerpo, minimizando a su vez la densidad y la consistencia de la conciencia (Locke, Hume y Berkeley).

Considerar la antropología cartesiana resulta muy significativo en el contexto que nos ubicamos, dado que, ha partido de la absolutización del yo. La certeza fundamental del hombre, su verdad primera, e indubitable es, según Descartes, la conciencia egológica que "piensa" el mundo: cogito ergo sum.

Advertí luego que, queriendo yo pensar de esa suerte que todo es falso, era necesario que yo, que lo pensaba, fuese alguna cosa; y observando que esta verdad"yo pienso, luego soy", era tan firme y segura que las más extravagantes supersticiones de los escépticos no son capaces de conmoverla, juzgué que podíarecibirla sin escrúpulo como el primer principio de la filosofía que andababuscando. (Descartes, 1970, p. 49-50)

Pero, la disputa entre Descartes y Hobbes aparecerá pronto, dado que, según Descartes debe aceptarse la distinción entre espíritu y materia, el primero es pensamiento, el segundo es extensión. Para Hobbes, en cambio, toda la realidad "es" corpórea. "Las facultades de la naturaleza humana pueden reducirse a cuatro especies: fuerza corporal, experiencia, razón, pasión” (Hobbes, 2000, p. 53). De esta manera, el alma no existe.

Por otra parte, en la época de Hobbes se están enfrentando dos facciones antagónicas en la lucha por el poder: los monárquicos y parlamentarios. Es una guerra civil en donde se enfrentan en un primer momento Carlos I contra un amplio sector de ciudadanos ingleses, conocidos como "parlamentarios". La confrontación viene de tiempo atrás, y desde sus inicios había tenido un carácter religioso. Ya en 1604 el rey Jacobo I, padre de Carlos había rehusado llegar a un acuerdo con los puritanos en cuestiones dogmáticas y de hechohabía disuelto el Parlamento en el año 1610 con el resentimiento de muchos. De esta manera, la tensión entre parlamentarios y monárquicos estará latente. Aunado a ello, la insistencia de Jacobo en proteger la idea del derecho divino de los reyes y su incapacidadde reconocer el carácter representativo del parlamento. Carlos I al recibir la corona británica que le dejó su padre en 1625 tendrá que hacer frente al antagonismo entre monárquicos y parlamentarios.

Los hechos históricos que acontecieron en Gran Bretaña durante los reinados de Jacobo Iy Carlos I, el posterior Protectorado de Cromwell y la restauración de la monarquía en Carlos II (1659) dan cuenta de la importancia que tuvo para los historiadores y para Hobbes al querer ofrecer una justificación racional de los hechos y una solución permanente que aseguren la convivencia pacífica ciudadana. (Hobbes, 2000, p. 9-12).

Hobbes (1588-1679) fue un filósofo muy bien relacionado en el ambiente académico de su época, llega a relacionarse con Bacon, Gassendi, Descartes (a quien realiza objecionesa sus Meditaciones metafísicas) y conoce personalmente a Galileo. Pero, su pensamientono goza de la fama de otros pensadores de su época. Su contemporáneo J. Locke (1632- 1704) tuvo 
mayor influencia siendo llamado "Padre del liberalismo clásico"1, quien influido por las ideas de F. Bacon (1561-1626), realizó una importante contribución a la teoría del contrato social en su obra Dos ensayos sobre el gobierno civil (1690). La idea de la naturaleza en Locke es cristiana, el hombre ha sido creado por Dios, por lo que el hombre no puede destruir su vida ni la de los demás hombres, porque no le pertenecen. Ysu condición natural es la de un ser libre. Dado que, el hombre lleva inserto el derecho yel deber de cuidar su vida, la comunidad ayudará a garantizar ese derecho en caso de que alguien la dañara o lo intentara. El Estado tendrá el deber de juzgar en caso de conflicto.Se trata pues de fundar un orden social o civil mediante un contrato mediante el cual la autoridad (El Estado) aplique la justicia en caso haya conflicto entre los hombres.

Por consiguiente, siempre que cierta cantidad de hombres se unen en una sociedad, renunciando cada uno de ellos al poder ejecutivo que les otorga la ley natural en favor de la comunidad, allí y solo allí habrá una sociedad política o civil (Locke, 1991, p. 266).

De este modo, en Locke el pacto civil es bastante limitado, otorgando facultades a la autoridad de intervenir en caso de conflictos que vienen de la propia ley natural, porque lo que se trata es garantizar la libertad e igualdad de todos asegurando sus derechos a la vida y la propiedad.

En cambio, el pensamiento político de Hobbes cimentado en un marcado materialismo como mencionamos líneas atrás-, analizará al ser humano y la sociedad desde lascondiciones puramente naturales. Considerado el fundador de la filosofía política moderna desenvuelve su pensamiento a partir de dos preguntas fundamentales: ¿Por quédebe existir el Estado? y ¿Cómo ha de existir? La necesidad de una fundamentación jurídica que tiene como base el contrato entre los hombres podrá ser el modo cómo se puede articular la paz y armonía en una sociedad donde imperan las pasiones egoístas. Suteoría contractualista es delineada en un contexto de guerra civil en Inglaterra donde se discute quién debe ocupar la soberanía; el rey o el parlamento. En su obra más conocida el Leviatán (1651) expondrá las condiciones jurídicas que regirán el Estado.

Nicolás Maquiavelo (1469-1527) en su obra El Príncipe (1513) ya había planteado que el gobernante no debía regir sus actos por normas morales o procedentes del derecho natural, sino que debe reconocer como una guía el bien del Estado. Si bien la distancia entre Maquiavelo y Hobbes van más allá de los 50 años podemos encontrar una similituden su concepción político-social y el contexto que les tocó vivir. Maquiavelo tiene que enfrentar la desunión de los estados italianos, divididos en cinco grandes estados: en el sur el reino de Nápoles, en el noreste el ducado de Milán, en el noreste la República Aristocrática de Venecia, la República de Florencia y en el centro, los Estados Pontificiosque resultaron ser

\footnotetext{
${ }^{1}$ Al pensador político se lo aprecia como el padre del liberalismo por sostener que todo gobierno surge de un pacto o contrato revocable entre individuos, con el propósito de proteger la vida, la libertad y la propiedad de las personas, teniendo los signatarios el derecho a retirar su confianza al gobernante y rebelarse cuando éste no cumple con su función. (Varnagy, p. 42)
}

revistaeduca@umch.edu.pe

revistas.umch.edu.pe 
los más duraderos y cohesionados en Italia ${ }^{2}$. Hobbes tendrá que convivir con los estragos de la guerra civil de Inglaterra, el apogeo de la revolución protestante y la guerra de los Treinta años. A ello habría que añadir que, ambos tienen poca estima a la Iglesia de Roma, la combaten y propugnan un liberalismo.

Los estados italianos en el contexto de Maquiavelo estaban divididos y luchaban entre ellos en la búsqueda de una mayor supremacía. (Vásquez, 2008, p. 13).

Los estados italianos en el contexto de Maquiavelo no sólo estaban divididos, no sólo ignoraban, entre sí, los estamentos básicos de la justicia, sino que luchaban entre ellos, ora por culpa de la Iglesia -incapaz de unirlos, pero lo suficientemente fuerte para mantenerlos separados mientras su poder no se vieraafectado-, ora por el grado de corrupción que las hacían vulnerables antecualquier ataque foráneo, ora por los tiranos italianos que hacían inviable una vida social débil, desordenada, pobre e infecunda, cuyos ciudadanos no tenían másinterés que el propio.

En este contexto, la frase "el fin justifica los medios" adjudicada a Maquiavelo tendrá una comprensión mucho amplia; dado que son se trata de cualquier fin, sino ese fin que es "el bien supremo de la patria" que consiste en la construcción y conservación del Estado.

\section{Pensamiento político de Hobbes}

Según Hobbes, T. (1994) la violencia en la que se encuentra inmersa nuestra sociedad manifiesta la voluntad egoísta de una persona o grupo de personas que no se deja limitar por nada ni por nadie. Los hombres se consideran como excepciones ellos mismos, se vena si mismos como de gran valía desmereciendo el valor de los demás hombres. Aunque si bien valoran a unos pocos por la fama de que gozan o por la coincidencia con ellos mismos, difícilmente llegan a creer que haya muchos tan sabios como ellos (p. 134). La desproporcionalidad en la consideración de las demás personas llega en ellos en tanto son incapaces de pensar que pueda haber más sabios que los sobrepasen. Curiosamente esta situación contrasta con la consideración natural o estructura ontológica del hombre, puesto según él mismo:

La naturaleza ha hecho a los hombres tan iguales en las facultades del cuerpo y del espíritu que, si bien un hombre es a veces, evidentemente más fuerte de cuerpo o más capaz de entendimiento que otro, cuando se considera en conjunto, la diferencia entre hombre y hombre no es tan importante que uno pueda reclamar (p. 127).

De aquí que, desde Hobbes la naturaleza del hombre responde a dos vertientes claramente distintos: una compuesta por las facultades y poderes naturales que pertenecen a la parte

\footnotetext{
${ }^{2}$ La unidad de Italia. Maquiavelo la desea ardientemente: sueña con una Italia unida, bajo la dirección de Florencia, y la proliferación de pequeños estados le parece desorden abominable y la principal causa que convertía a su país en presa codiciada y campo de batalla predilecto de las potencias europeas. Maquiavelo, N. (19879) Discurso sobre la primera década de Tito Livio . Alianza editorial Madrid
} 
animal y la otra constituida por los poderes y facultades naturales que pertenecen a la parte racional.

La naturaleza del hombre es la suma de sus facultades y poderes naturales, esto es, la nutrición, el movimiento, la reproducción, los sentidos, la razón, etcétera. Estos poderes son llamados unánimemente por nosotros, naturales. Son llamados, y están contenidos en la definición de hombre las palabras: animal y racional (Hobbes, 1987, p. 127)

Siguiendo esta forma de pensamiento, sería la propia animalidad como instinto que empuja la voluntad egoísta en seguir siempre y sin condiciones las propias inclinaciones y los propios intereses sin tener en cuenta a los demás y el daño que con ello se les pueda hacer. Lleva hasta a aprovecharse de los demás cuanto sea posible motivada por la ambición de poder y de riqueza que genera situaciones injustas.

La condición del hombre es una condición de guerra de todos contra todos, en la cual cada uno está gobernado por su propia razón, no existiendo nada, de lo que pueda hacer uso, que no le sirva de instrumento para proteger su vida contra sus enemigos. (Hobbes, 1994, p. 135).

Así, el estado de naturaleza del hombre propuesta por Hobbes, anterior a la organización social, es decir; "guerra de todos contra todos" (bellum ómnium contra omnes), es un poder que cada hombre posee es para garantizar la autoconservación.

El derecho de naturaleza, lo que los escritores comúnmente llaman jus naturae, es la libertad que cada hombre tiene de usar su propio poder como quiera, para la conservación de su propia naturaleza, es decir, de su propia vida, y por consiguiente, para hacer todo aquello que su propio juicio y razón considere como los medios más aptos para lograr ese fin. (Hobbes, 1994, p. 134)

El único criterio de moralidad es el egoísmo; la única regla de derecho natural, la propia utilidad; el único bien, la propia conservación y el provecho propio; la única medida de derecho, la ley del más fuerte. Todo está permitido. El hombre sometido al determinismo de sus pasiones, que le arrastran a conseguir su propio bien, su conservación, el placer y el bienestar para su cuerpo. Así, cada hombre puede usar a su arbitrio el propio poder para conservar su vida. Hasta aquí el individuo se enseñoreo en si mismo y mira el horizonte donde se proyecta su propio ser. Pero, sucede que todos, igual que él, tienen ese derecho natural igual a todo, incluso sobre el cuerpo y la vida de los demás.

Esta es la causa de que, si dos hombres desean la misma cosa, y en modo alguno pueden disfrutarla ambos, se vuelven enemigos, y en el camino que conduce al fin (que es, principalmente, su propia conservación y a veces su delectación tan sólo) tratará de aniquilarse o sojuzgarse uno a otro (Hobbes, 1994, p. 128)

Así, el hombre mirándose a sí mismo y preocupado en la satisfacción de sus propios deseos entra en un estado total de aislamiento que no se contenta con su propia conservación, sino 
que aspira también a apoderarse de los bienes materiales y a dominar a los demás. Cada individuo busca su propio bien, prescindiendo de los demás. Su propia naturaleza instintiva juega contra él mismo, dado que, su existir lo lleva a un enfrentamiento con los otros que no son diferentes a él y aspiran las mismas cosas que él aspira. Y como todos los hombres son iguales y libres, todos tienen derecho a todo y todossienten inclinación natural a las mismas cosas y a gozar de todos los bienes. De aquí resulta que cada uno se convierte para el otro en un enemigo al cual hay que destruir: "Elhombre es lobo del hombre" (Homo homini lupus). Cada hombre es para los demás un enemigo que se debe quitar cual piedra ubicada en el camino que no permite avanzar. Bajo esta filosofía, sólo queda la guerra donde la fuerza y el engaño son las dos virtudes cardinales.

En esta guerra de todos contra todos, se da una consecuencia que nada puede ser injusto. Las nociones de derecho e ilegalidad, justicia e injusticia están fuera de lugar. Donde no hay poder común, la ley no existe: donde no hay ley, no hay justicia. En la guerra, la fuerza y el fraude son las dos virtudes cardinales (Hobbes, 1994, p. 132)

Este estado natural propuesto por Hobbes sería desastroso si no se considerara ladimensión racional del hombre. Porque es por ley natural también que el hombre está sometido a las normas de la "recta razón", es decir, al racionamiento propio y verdaderoque cada uno hace sobre sus propias acciones que pueden ser útiles o perjudiciales a otroshombres. La misma razón dicta a los hombres una ley natural, por la cual se prohíbe hacerlo que acarrea la destrucción de la vida.

De aquí resulta un precepto o regla general de la razón, en virtud de la cual, cada hombre debe esforzarse por la paz, mientras tiene la esperanza de lograrlo; y cuando no pueda obtenerla, debe buscar y utilizar todas las ayudas y ventajas de la guerra. La primera fase de esta regla contiene la ley primera y fundamental de naturaleza, a saber: buscar la paz y seguirla. La segunda, la suma del derecho de naturaleza, es decir: defendernos a nosotros mismos, por todos los medios posibles. (Hobbes, 1994, p. 135)

La primera regla "Hay que buscar la paz y seguirla" puede ser parafraseada en la expresión "Hay que hacer el bien y evitar el mal" porque la consecuencia de una guerra sin cuartel sería nefasta para la supervivencia de cualquier individuo. Los horrores de la guerra sólo pueden traer resentimiento y más violencia en un espiral sin fin, generando así inseguridad, miseria y degradación humana. Por otra parte, la segunda regla conllevaa que los hombres busquen mecanismos de protección para salvaguardar la vida que es elmayor bien que cada uno posee. De esta manera, la ley de naturaleza establecida por la razón se basa en la necesidad de asegurar la propia conservación y, por lo tanto, de asegurar la paz. "Ley de naturaleza (lex naturalis) es un precepto o norma general, establecida por la razón, en virtud de la cual se prohíbe a un hombre hacer lo que puede destruir su vida o privarle de los medios de conservarla" (Hobbes, 1994, p. 134).

Pero, esta paz no podría conseguirse sólo con los esfuerzos aislados de los miembros de una 
sociedad. "Y aunque haya una gran multitud, si sus acuerdos están dirigidos según sus particulares juicios y particulares apetitos, no puede esperarse de ello defensa ni protección contra un enemigo común ni contra las mutuas ofensas" (Hobbes, 1994, p. 174). Se hace necesaria una instancia superior al que no se le pueda resistir aun juntandotodos los esfuerzos individuales, es decir, la autoridad. "No es la conjunción de un pequeño número de hombres lo que da a los Estados esa seguridad" (Hobbes, 1994, p. 173). El Estado en este caso, La autoridad mediante las facultades que posee: obligar, sancionar, persuadir... somete todas las voluntades de los particulares a una sola voluntadque está encaminada a establecer el orden, asegurar el bien común y la paz. De aquí que,es necesario el sometimiento de todas las voluntades de los particulares a una sola voluntad, que puede ser de una autoridad local o una institución gubernamental.

A su vez, los hombres deben comprometerse a lo que Hobbes llama un "pacto social", renunciando colectivamente a sus derechos naturales, poniéndolos íntegramente en manos de un solo individuo o asamblea (la autoridad) quienes deben cautelar el respeto entre los hombres. "Un Estado ha sido instituido cuando una multitud de hombres convienen y pactan, cada uno con cada uno, que un cierto hombre o asamblea de hombresse le otorgará, por mayoría, el derecho de representar a la persona de todos (es decir, de ser su representante)" (Hobbes, 1994, p. 179). De aquí que, existen la sociedad y el Estadoquienes conviven necesariamente mediante un pacto o contrato que fundamentalmente podrá garantizar no sólo la supervivencia de cada uno de sus miembros, sino también el progreso y bienestar común de todo el grupo humano. Mediante este pacto egoísta colectivo el hombre se sustrae determinados derechos y se los entrega a una instancia superior creada, el Leviatán, quien tiene que asegurar la supervivencia. De esta manera, ya no hay norma que regule la convivencia entre los hombres, sino ha sido creado un orden artificial.

El Estado como institución erigida por pacto entre los hombres llamada a garantizar la vida y el respeto de los derechos de todos puede en alguna manera desentenderse de los deberes que se le ha confiado; porque quien cumple primero no tiene seguridad que el otro cumplirá después, ya que los lazos de las palabras son demasiado débiles para refrenar la ambición humana, la avaricia, la cólera y otras pasiones de los hombres, si éstos no sienten el temor de un poder coercitivo. Pero, en este punto Hobbes extrañamentehace una excepción porque afirma que en un Estado civil donde existe un poder apto paraconstreñir a quienes, de otro modo, violarían su palabra, dicho temor ya no es razonable,y por tal razón quien en virtud del pacto viene obligado a cumplir primero, tiene el deberde hacerlo así (Hobbes, 1994, p. 142). 


\section{Conclusión}

La violencia siempre ha estado presente en la sociedad porque es la expresión de los intereses humanos que pretende imponerse frente a los hombres obedeciendo a su naturaleza intrínseca. Por ello, desde épocas antiguas se buscó regularlas o encauzarlas através de leyes y autoridades elegidas de entre los ciudadanos.

El pensamiento político de Hobbes debe situarse en el contexto filosófico y político que le tocó vivir. No podría argumentarse su teoría política el día de hoy para justificar la existencia y rol del Estado como su imperiosa intervención para regular los conflictos entre los hombres dado que, son incapaces de resolverlos entre ellos mismos. Hacerlo sería negar el derecho y capacidad de los hombres de poder discernir y saber elegir racionalmente lo que es auténticamente bueno y verdadero.

La estructuración respecto a las condiciones jurídicas que permitan darle al Estado su fundamentación ontológica resolviendo las guerras entre los hombres, tiene un fundamento contradictorio. La concepción materialista que desarrolla no le permite a Hobbes valorar la capacidad del hombre de aprender de sus propias experiencias; porqueincluso para Hume la experiencia es interpretada por categorías del pensamiento. Y, por otra parte, la capacidad de utilizar el diálogo para resolver sus conflictos en virtud de esarazón que es definitiva lo que le permitirá sobrevivir y evitar su propia destrucción.

Finalmente, según Hobbes la violencia en la que se encuentra inmersa nuestra sociedad y donde sus miembros son actores o espectadores de un mismo drama, hunde sus raíces enla voluntad egoísta y la incapacidad de proyectarse en el otro y ser capaz de reconocer los derechos propios y que son comunes a todos. La sociedad misma no ha evolucionado enbase al pacto social ya que el Estado los domina, negando de esta manera la capacidad del hombre de cooperar entre los hombres para la actividad social y la posibilidad de crearinstituciones para alcanzar fines comunes. 


\section{Referencias}

Cadavid, I. (2012) La justicia en el marco del estado griego. Revista Ratio Juris Vol 7, Nro. 15, pp 19-36 Recuperado: https://dialnet.unirioja.es/descarga/articulo/4277881.pdf

Cassirer, E. (1976) Antropología filosófica. Fondo de Cultura económica, México.

Cardona, P. (2008) Poder político, contrato y sociedad civil: de Hobbes a Locke. Revista Facultad de Derecho y Ciencias Políticas. Vol 38, Nro. 108/ p. 123-154, Medellín (Colombia). Recuperado:https://www.redalyc.org/pdf/1514/151413541006.pdf

De Romilly, J. (2010) La Grecia antigua contra la violencia, Traducción Jordi Terré, , España: Gredos

Descartes, R. (1970). Discurso del método. Madrid:

Fernández, J. (2015) La filosofía política según Maquiavelo. Guía de estudio para estudiantes de grado en filosofía, Madrid. Recuperado: https://eprints.ucm.es/37725/1/La\%20Filosofi\%CC\%81a\%20politica\%20segu\%CC\%8 1n\%20Maquiavelo.\%20Gui\%CC\%81a\%20de\%20estudios\%20para\%20estudiantes\%2 0de\%20Grado\%20en\%20Filosofi\%CC\%81a.pdf

Hobbes, T. (1987) La naturaleza humana o los elementos fundamentales de lapolítica, en Antologòa/Hobbes, edición de Enrique Linch, Barcelona, Península, p. 127. (1994) El Leviatán, Tomo I, Gernika, México.(2000) De Cive. Alianza ed, Madrid.

Honneth, A. (2009) Crítica del agravio moral. Patologías de la sociedadcontemporánea. Fondo de Cultura Económica de Argentina, S.A.

Locke, J. (1991) Dos ensayos sobre el gobierno civil. Espasa-Calpe, Madrid.

Ramirez, J. (2010) Thomas Hobbes y el Estado absoluto: el Estado de razón al Estadode terror. Universidad de Antioquia, Colombia.

Sacristán, M. \& Curto, A. (2007) Lecturas de filosofía moderna y contemporánea. Trtta, Madrid.

Strauss, L. \& Cropsey, J. (Compiladores) (1993) Historia de la filosofía política. Fondode Cultura Económica, México.

Várnagy, T. El pensamiento político de John Locke y el surgimiento del liberalismo. Recuperado. http://bibliotecavirtual.clacso.org.ar/ar/libros/moderna/cap2.pdf

Vásquez, M. (2008) El concepto de Estado en Thomas Hobbes. Universidad NacionalMayor de San Marcos, Lima (Perú) 
Venturelli, R. (2000) Maquiavello y su príncipe en el contexto de la cultura italiana del '500. En Ensayo sobre Latinoamericano de Argentina. publicación: Fortuna y virtud en la República Democrática.Maquiavello.

Tomás Várgany CLACSO, Consejo Ciencias Sociales. Ciudad Autónoma de Buenos Aires, Recuperado: http://biblioteca.clacso.edu.ar/ar/libros/maquiavelo/venturelli.pdf 